\title{
ГЕНДЕРНЫЕ РАЗЛИЧИЯ КОГНИТИВНЫХ ФУНКЦИЙ ПРИ ЦЕРЕБРОВАСКУЛЯРНОЙ ПАТОЛОГИИ
}

Аликулова Н. А., профессор, д. м. н.

Назарова Ж. А., дочент, к. м. н.

Рахматова С. Н., аспирант

Узбекистан, кафедра неврологии,

Ташкентский институт усовершенствования врачей

DOI: https://doi.org/ 10.31435/rsglobal_ws/31102018/6176

\section{ARTICLE INFO}

Received: 13 August 2018

Accepted: 11 October 2018

Published: 31 October 2018

\section{KEYWORDS}

gender,

cognitive function,

cerebral venous dysfunction in chronic

cerebral ischemia.

\begin{abstract}
Clinical, instrumental and neuropsychological examination was carried out in 110 patients with chronic brain ischemia of the 2nd degree on the background of hypertension of the 2 nd stage. The subjects were divided into 2 groups based on gender. Signs of venous cerebral dishelie valley significantly more cases in the group of women. It is shown that the group of women with cerebral venous Disgaea more patients had cognitive impairment (MMSE scale). Also, the low rate of induced cognitive potentials in the brain (the method of cognitive evoked potentials) was more pronounced in women than in men. It should be assumed that in hypertensive disease, the presence of concomitant cerebral venous dysfunction aggravates the course of cerebral ischemia, especially in women.
\end{abstract}

Citation: Аликулова Н. А., Назарова Ж. А., Рахматова С. Н. (2018) Gendernie Razlichiya Kognitivnih Funkcii pri Cerebrovaskulyarnoi Patologii. World Science. 10(38), Vol.1. doi: 10.31435/rsglobal_ws/31102018/6176

Copyright: (C) 2018 Аликулова Н. А., Назарова Ж. А., Рахматова С. Н. This is an open-access article distributed under the terms of the Creative Commons Attribution License (CC BY). The use, distribution or reproduction in other forums is permitted, provided the original author(s) or licensor are credited and that the original publication in this journal is cited, in accordance with accepted academic practice. No use, distribution or reproduction is permitted which does not comply with these terms.

Цереброваскулярные заболевания (ЦВЗ) являются одной из основных проблем современной медицины. Известно, что в последние годы структура сосудистых болезней мозга меняется за счет нарастания ишемических форм. Это обусловлено повышением удельного веса артериальной гипертензии и атеросклероза как основной причины цереброваскулярной патологии. При изучении отдельных форм нарушений мозгового кровообращения первое место по распространенности занимает хроническая ишемия (ХИМ). $(5,7)$

Хроническая ишемия головного мозга рассматривается как единый патологический процесс, включающий в себя разнообразные ишемические нарушения мозгового кровообращения, возникающие вследствие несоответствия мозгового кровотока метаболическим потребностям мозговой ткани, ведущее место в этиологии которых принадлежит атеросклерозу церебральных [7].

Изучение когнитивных (познавательных) нарушений (КН), обозначаемых в отечественной литературе также как нарушение высших психических функций, при сосудистых заболеваниях головного мозга имеет важное значение, обусловленное медицинскими и социальными аспектами проблемы. Деменция - выраженное нарушение ВПФ по данным А. С. Хендерсон (1995) ежегодно диагностируется у 1\% лиц 65 лет и старше. В связи с большой распространенностью сосудистых заболеваний мозга и постарением населения в последние годы в большинстве экономически развитых стран наблюдается значительный рост числа больных с сосудистой деменцией. $[2,3,6]$ 
Несмотря на интенсивное изучение морфологического субстрата КН при ЦВЗ, патофизиологические механизмы их формирования остаются недостаточно изученными. В литературе отсутствует детальный нейропсихологический и электрофизиологический анализ КН на фоне ЦВЗ, в зависимости от полового деморфизма. Актуальность проблемы, а также некоторые неизученные и спорные вопросы определили цели и задачи настоящей работы.

Цель работы: анализ нейропсихологических и электрофизиологических отличий КН при ХИМ на фоне гипертонической болезни (ГБ) в зависимости от пола, с уточнением нейрофизиологических показателей КВП.

Материал и методы исследования. Нами исследовано 110 пациентов с ХИМ 2 стадии на фоне гипертонической болезни II (ГБ), находившихся на лечении в неврологическом отделении Областной Соматической больницы. Все обследуемые были разделены на 2 группы:

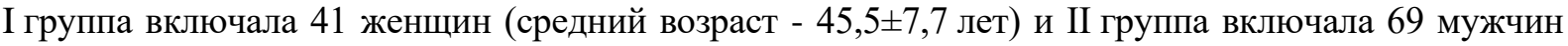
(средний возраст - 51,2 $\pm 6,7$ лет). Обе группы были сопоставимы по возрасту и диагнозам.

Соотношение по полу у обследованных больных было 1:1,7 в пользу мужчин. Средний возраст пациентов составил $62,8 \pm 8,3$ года. Средняя продолжительность заболевания в наших исследованиях составила 5,7 лет.

Контрольную группу составили 20 здоровых лиц с нормальным уровнем артериального давления и без стенозирующих заболеваний сосудов мозга. Средний возраст в этой группе составил 53,1 \pm 9 года.

Методы исследования включали общеклинические методы: общий анализ крови и мочи. Биохимические исследования включали коагулограмму крови, время свертывания крови, офтальмоскопия. Обследуемым также были проведены нейрофизиологические методы исследования: УЗДГ артерий и вен головы, МРТ головного мозга, ЭЭГ исследования головного мозга, когнитивные вызванные потенциалы мозга $(1,4)$, а также исследование высших корковых функций нейропсихологическим тестом MMSE.

Обсуждение результатов исследования. В ходе проведенного анализа, отмечено, что в группе у женщин у $29(70,1 \%)$ выявлены признаки церебральной дисгемии, в группе мужчин этот показатель был достоверно ниже - 25 (36,2\%) случаев. В группе женщин умеренные КН были у большего числа больных (65,9\%), что достоверно выше показателей в группе у мужчин, где число случаев умеренных КН было наименьшим и составило лишь 34,8\%. (табл.1.).

Таблица 1. Выраженность КН у больных с ХИМ на фоне ГБ ІІ в зависимости от пола.

\begin{tabular}{|c|c|c|c|c|c|c|}
\hline Степени КН & Женщины & $(n=41)$ & MMSE (баллы) & Мужчины & $(n=69)$ & MMSE (баллы) \\
\hline & $\mathrm{n}$ & $\%$ & & $\mathrm{n}$ & $\%$ & \\
\hline Легкие КН & 14 & $34,1 \% *$ & $21,5 \pm 1,2$ & 45 & $65,2 \%$ & $22,1+0,8$ \\
\hline Умеренные КН & 27 & $65,9 \% *$ & $15,7+0,9$ & 24 & $34,8 \%$ & $17,5+1,4$ \\
\hline
\end{tabular}

Здесь и далее Примечание: * - различия достоверны между группами

Также были исследована выраженность КН по шкале MMSE у мужчин и женщин в зависимости от наличия у них симптомов церебральной венозной дисгемии (ВЦД). Как видно из таблицы 2 в группе женщин с ВЦД случаев с УКН было достоверно выше, чем в группе без ВЦД, как среди женщин, так и среди мужчин. В группе мужчин с ВЦД соответствующие показатели были ниже по сравнению с группой женщин с ВЦД, где достоверных различий обнаружено не было.

Наряду с клинико-неврологическими исследованиями были включены в блок исследований, помимо регистрации ЭЭГ, исследования когнитивных вызванных потенциалов (P300) (Goodin D.S., Aminoff M.J. 1986). Когнитивные вызванные потенциалы (КВП) были выбраны в связи с тем, что они позволяют оценивать эндогенные события, происходящие в мозге и связанные с распознаванием и запоминанием предъявляемых стимулов (Гнездицкий В.В., 1997). 
Таблица 2. Выраженность КН у мужчин и женщин в зависимости от наличия признаков ВЦД.

\begin{tabular}{|c|c|c|c|c|c|c|}
\hline & \multicolumn{3}{|l|}{ группа с ВЦД } & \multicolumn{3}{|l|}{ группа без ВЦД } \\
\hline $\begin{array}{l}\text { Степени } \\
\text { КН }\end{array}$ & MMSE(баллы) & Женщины & $(n=29)$ & MMSE(баллы) & Женщины & $(n=12)$ \\
\hline & & $\mathrm{n}$ & $\%$ & & $\mathrm{n}$ & $\%$ \\
\hline Легкие КН & $20,3+0,7$ & 4 & $13,8 \%$ & $22,3+0,2$ & 8 & $66,7 \%$ \\
\hline $\begin{array}{l}\text { Умеренные } \\
\text { КН }\end{array}$ & $13,1+1,5 *$ & 25 & $86,2 \%$ & $17,1+1,1$ & 3 & $25,0 \%$ \\
\hline $\begin{array}{l}\text { Степени } \\
\text { КН } \\
\end{array}$ & MMSE(баллы) & Мужчины & $(n=25)$ & MMSE(баллы) & Мужчины & $(n=44)$ \\
\hline & & $\mathrm{n}$ & $\%$ & & $\mathrm{n}$ & $\%$ \\
\hline Легкие КН & $22,1+1,2$ & 9 & $36,0 \%$ & $22,6+0,2$ & 36 & $81,8 \%$ \\
\hline $\begin{array}{l}\text { Умеренные } \\
\text { КН }\end{array}$ & $15,6 \pm 0,4$ & 14 & $56,0 \%$ & $18,6+1,2$ & 8 & $18,2 \%$ \\
\hline
\end{tabular}

Нейрофизиологические исследования нами проведены 46 больным первой и второй групп. Результаты исследований сопоставлялись с показателями КГ. Данные представлены в таблице 3

Из представленной таблицы 3 , видно, что основные показатели КВП у женщин и мужчин имели различия. Так, были отмечены достоверные различия по латентности Р300. У мужчин этот показатель был равен $397,85 \pm 63,21$ мс, тогда как у женщин $-368,75 \pm 53,01$ мс.

По остальным изученным параметрам различия были не достоверны. При сопоставлении показателей КВП у больных первой и второй группы, нами отмечено удлинение показателей латентности по всем отведениям, с сохранностью разницы показателей у больных с лево- и правополушарной локализацией. Хотя различия в показателях второй и первой группы носили недостоверный характер, они имели большие значения, что соответствовало более грубым когнитивных нарушениям. Следовательно, регистрация когнитивных вызванных потенциалов позволяет получить дополнительную информацию о состоянии когнитивной сферы у больных с ХИМ.

Таблица 3. Параметры вызванных потенциалов Р300 у обследованных больных с ХИМ в зависимости от пола.

\begin{tabular}{|l|l|l|l|l|}
\hline Параметры & отведения & КГ & Женщины $(\mathrm{n}=28)$ & Мужчины $(\mathrm{n}=18)$ \\
\hline & & & & \\
\hline Латентность P3, мс & $\mathrm{C} 3$ & $351,9 \pm 24,3$ & $368,75 \pm 53,01 * \wedge$ & $397,85 \pm 63,21$ * \\
\hline & $\mathrm{C} 4$ & $341,8 \pm 26,3$ & $367,62 \pm 52,63 * \wedge$ & $389,25 \pm 61,34$ * \\
\hline $\begin{array}{l}\text { Амплитуда N2/P3, } \\
\text { мкB }\end{array}$ & $\mathrm{C} 3$ & $5,2 \pm 3,28$ & $7,50 \pm 3,30$ & $7,81 \pm 3,29$ \\
\hline & $\mathrm{C} 4$ & $5,6 \pm 2,91$ & $7,59 \pm 3,0$ & $7,6 \pm 2,9$ \\
\hline Латентность N2, мс & $\mathrm{C} 3$ & $268,4 \pm 41,7$ & $255,81 \pm 34,14$ & $285,91 \pm 39,1$ \\
\hline & $\mathrm{C} 4$ & $269 \pm 47,2$ & $251,18 \pm 32,67$ & $271,18 \pm 22,7$ \\
\hline Латентность N3, мс & $\mathrm{C} 3$ & $457,2 \pm 54,3$ & $460,40 \pm 77,82$ & $465,40 \pm 78,27$ \\
\hline & $\mathrm{C} 4$ & $451,7 \pm 60,3$ & $461,86 \pm 79,84$ & $465,68 \pm 74,48$ \\
\hline $\begin{array}{l}\text { Амплитуда N3/P3, } \\
\text { мкВ }\end{array}$ & $\mathrm{C} 3$ & $6,1 \pm 6,37$ & $6,98 \pm 4,41$ & $6,83 \pm 4,18$ \\
\hline & $\mathrm{C} 4$ & $8,25 \pm 6,89$ & $6,84 \pm 3,76$ & $6,84 \pm 3,69$ \\
\hline
\end{tabular}

Примечание: * - различия достоверны между группой мужчин и КГ.

$\wedge$ - различия достоверны между группой мужчин и группой женщин.

При поражении левого полушария отмечалось более значительное снижение амплитуды и увеличение латентности пика Р300, что свидетельствовало о большей выраженности когнитивных нарушений и соответствовало данным нейропсихологического обследования. Латентность компонента N2 была больше во всех отведениях у больных с поражением правого полушария, что, вероятно, было связано с преимущественно гностической функцией данного полушария и, как следствие, нарушением процессов опознания стимулов. 
В заключении можно сказать что, нейропсихологическое обследование и когнитивные вызванные потенциалы являются важными методами оценки состояния высших психических функций у с ХИМ, позволяющими оценить степень вовлечения в патологический процесс пораженные отделы мозга, а также функциональное состояние головного мозга в целом. Исследование показало отличия нейропсихологических показателей в зависимости от пола, в группе у женщин наблюдались достоверно более выраженные КН и более низкая скорость проведения вызванных когнитивных потенциалов в головном мозге, в отличии от мужчин. Причем показатели по шкале MMSE в группе женщин в ВЦД были также достоверно ниже соответствующих показателей обследуемых женщин без ВЦД, и балльная выраженность соответствующих показателей также была выше по сравнению с группой мужчин как с ВЦД, так и без ВЦД. Следует предположить, что при гипертонической энцефалопатии наличие венозной дисциркуляции головного мозга отягощает течение церебральной ишемии, и представители женского пола находятся в группе риска.

Полученные данные необходимо учитывать при лечении больных с ХИМ на фоне гипертонической болезни, и, рекомендовать пациентам с данной патологией, особенно женского пола, раннюю профилактику когнитивных нарушений головного мозга, которая включает регулярную адекватную базисную терапию артериальной гипертензии и применение курсов венотонизирующих, ноотропных и нейротрофических препаратов.

\section{ЛИТЕРАТУРА}

1. Алёшина Е. Д., Коберская Н. Н., Дамулин И. В. Когнитивный вызванный потенциал Р 300 : методика, опыт применения, клиническое значение // Ж. неврологии и психиатрии. - 2009. № 109(8), - С. 77-84.

2. Богданова А. Р., Богданов Р. Р., Мазо В. К., Феофанова Т. Б. Когнитивные нарушения при дисциркуляторной энцефалопатии и ожирении // Consilium medicum. - 2013. - № 15(2). - С. 46-51.

3. Боголепова А. Н. Когнитивные нарушения у больных с цереброваскулярной патологией // Лечение нервных болезней. - 2011 - № 3(8). - С. 16-21.

4. Гнездицкий В. В., Ревенок Е. В., Корепина О. С., Калашникова Л. А., Брутян А. Г. Анализ Р 300 при когнитивных нарушениях у больных с сосудистыми заболеваниями головного мозга // В трудах конференции «Ишемия мозга». - Спб., 1997. - С. 41-45.

5. Гусев Е. И., Боголепова А. Н. Когнитивные нарушения при цереброваскулярных заболеваниях. М.: МЕДпресс-инфом, 2013.

6. Ревенок Е. В., Гнездицкий В. В., Корепина О. С. Вызванные потенциалы в оценке старения и деменции // В кн. Гнездицкий В. В., Шампинова А. М. (ред.) Опыт применения вызванных потенциалов в клинической практике. - М.: АОЗТ «Антидор», 2001. - С. 160-182.

7. Резков Г. И. Хронические сосудистые заболевания головного мозга: методические рекомендации. M., 2008.

8. Jason D. Yeatman, Brian A. Wandell, Aviv A. Mezer. Lifespan maturation and degeneration of human brain white matter. //Nature Communications volume5, Article number: 4932 (2014) 